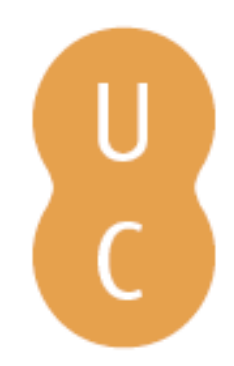

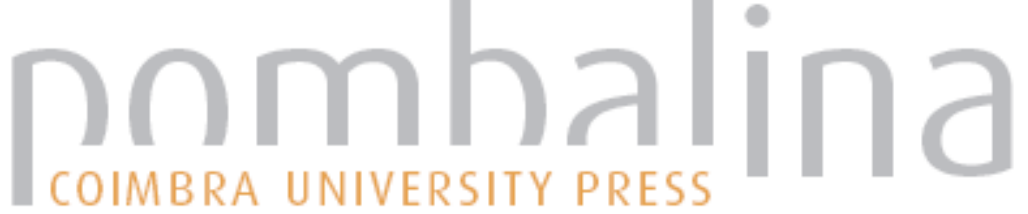

\section{Das mais puras memórias}
Autor(es):
Amaral, Ana Luísa
Publicado por: Imprensa da Universidade de Coimbra
URL persistente:
URI:http://hdl.handle.net/10316.2/42359
DOI:
DOI:https://doi.org./10.14195/978-989-26-1308-6_45

Accessed : $\quad$ 26-Apr-2023 15:58:52

A navegação consulta e descarregamento dos títulos inseridos nas Bibliotecas Digitais UC Digitalis, UC Pombalina e UC Impactum, pressupõem a aceitação plena e sem reservas dos Termos e Condições de Uso destas Bibliotecas Digitais, disponíveis em https://digitalis.uc.pt/pt-pt/termos.

Conforme exposto nos referidos Termos e Condições de Uso, o descarregamento de títulos de acesso restrito requer uma licença válida de autorização devendo o utilizador aceder ao(s) documento(s) a partir de um endereço de IP da instituição detentora da supramencionada licença.

Ao utilizador é apenas permitido o descarregamento para uso pessoal, pelo que o emprego do(s) título(s) descarregado(s) para outro fim, designadamente comercial, carece de autorização do respetivo autor ou editor da obra.

Na medida em que todas as obras da UC Digitalis se encontram protegidas pelo Código do Direito de Autor e Direitos Conexos e demais legislação aplicável, toda a cópia, parcial ou total, deste documento, nos casos em que é legalmente admitida, deverá conter ou fazer-se acompanhar por este aviso.

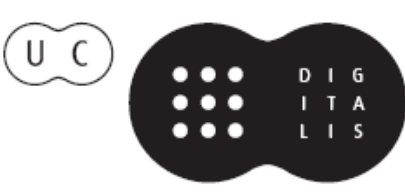





\section{DAS MAIS PURAS MEMÓRIAS}

Ana Luísa Amaral

\section{Do que chamamos academia}

"Isto está muito bem, Ana Luísa. Agora, é preciso reduzir para 20 páginas. . .”, disse-me a Maria Irene sentada à secretária, no seu gabinete. Estava-se nos idos de 1980, e "isto" era o capítulo que eu tinha escrito, para as Provas de Aptidão Pedagógica e Capacidade Científica, sobre a recepção crítica a King Lear. O capítulo tinha 80 páginas e reduzi-las a 20 foi uma aprendizagem que nunca esqueci. O gabinete era amplo, tinha um sofá fundo de pele gasta e um cinzeiro de pé, ao lado. Acolhedor. E eu, em choque, fumava desenfreadamente enquanto conversávamos.

Uns meses depois, o tempo apertando, a morte da Cláudia aos quinze anos, a Cláudia que era para mim uma irmã mais nova, a irmã que nunca tive, a sua morte brutal a travar-me a escrita do último capítulo: a morte de Cordelia. Eu, muito grávida, a viajar entre Porto e Coimbra, para discutir esse último capítulo. E a Maria Irene sempre lá, a apoiar-me. Guardo ainda a arguição que depois fez e me deu, ainda escrita à mão, do meu King Lear: Tragédia da Linguagem. Nessa arguição, a Maria Irene deteve-se numa epígrafe que eu escolhera, dando-me espaço para, a partir dela, falar da peça. E fez notar o esforço sobre-humano a que alguns trabalhos 
obrigam. Sabendo da minha dor. A partir dos afectos e da admiração, começava a minha paixão por Shakespeare.

Passado algum tempo, pedi-lhe orientação para o doutoramento. Primeiro, apresentei-lhe uma proposta insanamente chamada "Espaços e tempos de poesia", um projecto de 30 páginas, em que eu começava em Milton e acabava em Sylvia Plath. Claro que o projecto foi desfeito, cortado, passado a 4 páginas, e o seu assunto estabilizou-se na poesia e na poética de Sylvia Plath, Anne Sexton e Elizabeth Jennings.

Demorei um ano (entre idas a Coimbra, no Intercidades, ainda com carruagens fechadas) a resolver que aquelas três poetas deviam ser substituídas. É que entretanto, durante um almoço-reunião, a Maria Irene passou-me, juntamente com os primeiros livros que me deu sobre feminismo (The Female Eunuch, The Feminine Mystique), os poemas de Emily Dickinson, perguntando-me "Conhece?". Eu não conhecia. No comboio, de regresso a casa, folheei o livro e não percebi nada. Até que alguns dias depois, tarde de madrugada, deparei-me com um poema que dizia "If the stillness is Volcanic / In the human face / When upon a pain Titanic / Features keep their place". E tudo fez sentido. Como uma epifania.

Passaram-se uns meses até que nos tornámos a ver, num encontro da Associação Portuguesa de Estudos Anglo-Americanos. Foi então que lhe perguntei: "E se fosse Sylvia Plath e Emily Dickinson?". E a resposta da Maria Irene: "Acho muito bem, Ana Luísa. Mas precisa mesmo de Plath?". Assim, num intervalo entre comunicações e mesas-redondas, começava a minha segunda paixão que havia de ter como resultado uma tese de doutoramento chamada Emily Dickinson: Uma poética de excesso.

Demorei muito tempo a escrever a tese. Fizemos muitos almoços-reuniões (um hábito estrangeiro para a minha Faculdade, mas que a Maria Irene sempre manteve com os seus orientandos e que nós depois, orientadores já, haveríamos de replicar). Ultrapassados os 
prazos para a entrega da tese, não sei o que aconteceria se a Maria Irene não me tivesse telefonado a dizer, sobre o último capítulo, que tratava do espaço em Emily Dickinson: "Corte esse capítulo, faça as revisões finais e mande-me. Já chega, Ana Luísa!”. Chegou, claro. Mas nunca a publiquei, à tese. A Maria Irene ainda hoje fala disso, ainda me diz como sente pena por eu não o ter feito. E ainda hoje eu the respondo sempre da mesma maneira: ah, é porque publiquei livros de poemas. O que me leva à segunda parte deste testemunho:

\section{Do que chamamos poesia}

Um dia mandei à Maria Irene uns poemas pelo correio. Um desses poemas, com ecos do Rei Lear, dizia assim: "Se calhar o silêncio era silêncio apenas / E a minha voz, fantasma, / E aquela voz, ausência". Outro era sobre o Minotauro e terminava: "O homem-touro nunca saíra da caverna, e Teseu, ao entrar, tinha a força do sol a seu favor". No encontro seguinte, a pergunta chegou: "São seus, Ana Luísa?". E eu, tímida, a dizer que sim. Deixei mais poemas. Alguns meses depois, recebia um postal: "A Ana Luísa é mesmo poeta". Aquele "mesmo" sublinhado" teve um efeito muito semelhante ao que escreveu Emily Dickinson ao falar da leitura da poesia: "quando sinto o meu corpo tão frio que fogo nenhum o pode aquecer. ... Foi o que senti, ao ler o postal.

Estávamos em 1989. De vez em quando, a Maria Irene dizia-me "prepare um livro, que eu escrevo-lhe um posfácio". Eu lá ia "preparando" o livro (que escrever poemas é bem mais simples do que preparar livros). E um dia, na Via Latina, já estava o livro aprontado e com o estranho título $A$ impossível sarça, saiu um artigo da Maria Irene chamado "O sexo dos poetas: A propósito de uma nova voz na poesia portuguesa". Nesse artigo, a Maria Irene falava do meu livro, dizendo estar ele ainda à espera de editor - o que era verdade. 
O editor chegaria depois, era Soveral Martins e dirigia a cooperativa editorial Fora do Texto. O livro acabou por mudar o seu título para Minha Senhora de Quê, e teve, como prometido, um magnífico posfácio da Maria Irene. A Maria Irene foi, com a generosidade e a grandeza que todos lhe conhecemos, a primeira pessoa a escrever sobre a minha poesia. Desde então, é das primeiras pessoas a ler os poemas que escrevo.

Lembro-me de ir buscar o livro à estação de comboios das Devesas. De um estranho amarelo torrado, o livro tinha três meninas na capa e estava cheio de gralhas (a editora acabara de comprar computadores e dissera-me que não era preciso ver provas). O posfácio tinha também gralhas. A Maria Irene a protestar: "Mas como é possível que não tenha visto, Ana Luísa?". Apesar de tudo, em 1998, para a reedição do livro, já pela Quetzal, mantido o posfácio, a Maria Irene escreveria um prefácio. E o livro ficaria assim, acolhido e abrigado pelas suas palavras. Dessa vez, sem gralhas. . .

\section{Do que chamamos vida - que é tudo}

Podia aqui contar muitas coisas. Memórias soltas. Umas, pequenas, essas de que a vida é feita; outras, maiores, que a fazem também, à vida. Como a morte do meu pai, ou a morte do Paulo, o meu maior amigo, o irmão que nunca tive, e o apoio da Maria Irene. A sua amizade. As vezes todas em que eu estava escura e ela me escreveu, sempre com uma palavra de ternura ou de alento. "Põe-te guicha". Eu, curiosa, a ir ver ao dicionário o que era 'guicha'. Ou um encontro, há muitos mais anos, num café em Londres, onde eu tinha ido, com uma carta sua de recomendação, fazer investigação na British Library. Combináramos o encontro na Universidade de Londres e depois, nesse café, a Maria Irene a dizer-me: "Deixe lá cair o Doutora, Ana Luísa. Trate-me por 'Maria Irene'”. Custou-me, 
a princípio. Como me custou depois o degrau seguinte: "Ana Luísa, trata-me por tu". O incontável número de cartas de recomendação que me fez. A paciência infinita com que leu e corrigiu cartas minhas de pedidos de bolsa e artigos meus, antes de eu os enviar para publicação. Os livros de poesia que me apresentou e os tão belos textos que escreveu sobre a minha poesia. Uma carta longa que lhe mandei, no início dos anos 1990, a contar-lhe coisas da minha vida, e a sua resposta, numa carta igualmente longa, atenta, generosa, que está ali religiosamente guardada, dentro de uma gaveta da minha secretária, ao lado de um estranho testamento que um dia escrevi e em que deixo a guarda dos meus poemas inéditos a três pessoas: à minha filha, à Lurdes, minha outra grande amiga - e à Maria Irene.

O que hoje sou como professora, como investigadora, mas sobretudo como pessoa, devo-o, em grande, em imensa parte, à Maria Irene: à sua ética, ao seu saber, à sua dimensão humana. À sua amizade. Nos agradecimentos da minha tese de doutoramento, a última frase é-lhe dedicada: "As palavras que não chegam". Essa frase transitou para a primeira página da minha poesia reunida, Inversos, 1990-2010. "Vinte anos volvidos, a Maria Irene Ramalho: as palavras que não chegam", diz no livro. A Rita, a minha única filha, não se importou. Ela sabe como a Maria Irene me foi e é marcante. Aliás, a palavra correcta é fundamental. Ou basilar. Ou uma palavra que sugira esteio, alicerce. Fio de prumo.

Quando, há uns meses, fiz sessenta anos, a Rita decidiu organizar-me uma festa grande. E perguntou-me se havia alguém especial que eu quisesse presente. Nessa festa, junto à minha filha, à minha mãe, aos meus amigos mais queridos do Porto, que são muitos e eu não posso aqui enumerar, estava a Isabel, de Lisboa, e estavam os amigos de Coimbra, como a Graça, a São, o Tó, ou a outra Isabel. E estava a primeira pessoa que a Rita contactou: a Maria Irene. Para lumes assim, irredutíveis, não chegam as palavras. 